\title{
Antiferromagnetic Oxide Thin Films for Spintronic Applications
}

\author{
Saima Afroz Siddiqui ${ }^{1}$, Deshun Hong ${ }^{2}$, John E. Pearson ${ }^{2}{ }^{\mathbb{D}}$ and Axel Hoffmann ${ }^{1, *(\mathbb{C}}$ \\ 1 Materials Research Laboratory, Department of Materials Science and Engineering, \\ University of Illinois at Urbana Champaign, Urbana, IL 61801, USA; saimas@illinois.edu \\ 2 Materials Science Division, Argonne National Laboratory, Lemont, IL 60439, USA; dhong@anl.gov (D.H.); \\ pearson@anl.gov (J.E.P.) \\ * Correspondence: axelh@illinois.edu
}

Citation: Siddiqui, S.A.; Hong, D.; Pearson, J.E.; Hoffmann, A. Antiferromagnetic Oxide Thin Films for Spintronic Applications. Coatings 2021, 11, 786. https://doi.org/ 10.3390/coatings11070786

Academic Editor: Paolo Mele

Received: 31 May 2021

Accepted: 24 June 2021

Published: 30 June 2021

Publisher's Note: MDPI stays neutral with regard to jurisdictional claims in published maps and institutional affiliations.

Copyright: (c) 2021 by the authors. Licensee MDPI, Basel, Switzerland. This article is an open access article distributed under the terms and conditions of the Creative Commons Attribution (CC BY) license (https:// creativecommons.org/licenses/by/ $4.0 /)$.

\begin{abstract}
Antiferromagnetic oxides have recently gained much attention because of the possibility to manipulate electrically and optically the Néel vectors in these materials. Their ultrafast spin dynamics, long spin diffusion length and immunity to large magnetic fields make them attractive candidates for spintronic applications. Additionally, there have been many studies on spin wave and magnon transport in single crystals of these oxides. However, the successful applications of the antiferromagnetic oxides will require similar spin transport properties in thin films. In this work, we systematically show the sputtering deposition method for two uniaxial antiferromagnetic oxides, namely $\mathrm{Cr}_{2} \mathrm{O}_{3}$ and $\alpha-\mathrm{Fe}_{2} \mathrm{O}_{3}$, on A-plane sapphire substrates, and identify the optimized deposition conditions for epitaxial films with low surface roughness. We also confirm the antiferromagnetic properties of the thin films. The deposition method developed in this article will be important for studying the magnon transport in these epitaxial antiferromagnetic thin films.
\end{abstract}

Keywords: chromium oxide; hematite; reactive magnetron sputtering; epitaxial thin film; roughness; antiferromagnetic oxides

\section{Introduction}

Antiferromagnets have gained renewed interest due to their capability to support spin currents via their magnon excitations. This was first recognized in spin pumping experiments, where it was observed that spin currents can be conducted through much thicker insulating antiferromagnetic layers than conventional dielectric materials [1,2]. Subsequently, it was shown that the magnon contribution to heat currents in insulating antiferromagnets can give rise to spin Seebeck effects and therefore can be used to inject spin currents into adjacent metallic layers [3-5]. While this thermal spin current injection relied on incoherent magnons, it has in the meantime also been shown that spin current injection from coherently excited magnons is also possible [6,7]. More importantly, nonlocal transport measurements demonstrated the possibility to electrically inject and detect magnons in both $\mathrm{Cr}_{2} \mathrm{O}_{3}$ [8] and $\alpha-\mathrm{Fe}_{2} \mathrm{O}_{3}[9,10]$. Magnons can propagate over micrometer distances in both of these materials. Lastly, it has also been shown that current induced inhomogeneous temperature profiles can give rise to strains and thus allow to manipulate the magnetic structure within the insulating antiferromagnets [11]. Thus, antiferromagnetic insulators and specifically oxides are promising materials for spintronics applications (i.e., logic, memory, thermoelectric etc.) as they have zero resistive loss, tera-hertz spin dynamics and are immune to high magnetic fields [12,13]. In order to realize their full potential these applications require these antiferromagnetic materials in the thin film form [14].

In this article, we show the systematic variation of the thin films properties (film roughness and strain) of two antiferromagnetic hexagonal materials (i.e., $\mathrm{Cr}_{2} \mathrm{O}_{3}$ and $\alpha$ $\mathrm{Fe}_{2} \mathrm{O}_{3}$ (Hematite)) by varying the deposition parameters (i.e., $\mathrm{O}_{2}$ flow rate, deposition temperature and deposition pressure). There have been a few studies on the deposition of 
these oxides in thin film form [15-17], in particular, on (0001) sapphire. We here show the epitaxial growth of these antiferromagnetic thin films on [1120] sapphire substrates. These antiferromagnetic materials show no residual magnetism within the thickness ranging from 10 to $200 \mathrm{~nm}$. However, the Morin transition was observed in $\alpha-\mathrm{Fe}_{2} \mathrm{O}_{3}$ with thickness above $200 \mathrm{~nm}$. The deposition process developed in this article will enable many exciting spintronic studies in these antiferromagnetic oxides.

\section{Deposition Methods and Characterizations}

In this work, we deposited $\mathrm{Cr}_{2} \mathrm{O}_{3}$ and $\alpha-\mathrm{Fe}_{2} \mathrm{O}_{3}$ by using radio frequency (RF) magnetron sputtering at high temperature from $2^{\prime \prime} \mathrm{Cr}$ and Fe sputtering targets, respectively, on (11-20) $\mathrm{Al}_{2} \mathrm{O}_{3}$ (A-plane sapphire) substrates in the presence of both oxygen and argon. Initially, we varied the oxygen flow rate from 1.0 to $5.0 \mathrm{sccm}$ while keeping the argon flow rate at $70 \mathrm{sccm}$ and the chamber pressure at $3 \mathrm{mTorr}$. Here, we calibrated the deposition rate of $\mathrm{Cr}_{2} \mathrm{O}_{3}$ and the $\alpha-\mathrm{Fe}_{2} \mathrm{O}_{3}$ using the crystal monitor. The temperature of the substrate was varied from 625 to $750{ }^{\circ} \mathrm{C}$ and the deposition pressure was varied from 2 to $5 \mathrm{mTorr}$ for both $\mathrm{Cr}_{2} \mathrm{O}_{3}$ and $\alpha-\mathrm{Fe}_{2} \mathrm{O}_{3}$.

The crystal orientation and the deposition rate of the epitaxial oxide films are characterized by $\mathrm{X}$-ray diffraction (XRD) and X-ray reflectivity (XRR), respectively, using the Bruker D8 Advance XRD System (Bruker Corporation, Billerica, MA, USA) with a monochromatic $\mathrm{Cu} \mathrm{K} \alpha$ source with a wavelength of $1.54 \AA$. The roughness of the films is characterized by both XRR and atomic force microscopy (AFM) and the magnetic properties are characterized by superconducting quantum interference device (SQUID) magnetometer (Quantum Design North America, San Diego, CA, USA).

\section{Results and Discussions}

\subsection{Crystal Structures of Epitaxial Oxide Films}

Figure 1 shows the $\mathrm{XRD}$ data of the $20 \mathrm{~nm} \mathrm{Cr} \mathrm{O}_{3}$ epitaxial films grown at $675{ }^{\circ} \mathrm{C}$ with an oxygen flow of $2.5 \mathrm{sccm}$ and chamber pressure of $5 \mathrm{mTorr}$. The base pressure of the chamber was $3 \times 10^{-8}$ Torr. After the deposition, the films were annealed at $700{ }^{\circ} \mathrm{C}$ for one hour at $2 \mathrm{mTorr}$ in the presence of oxygen at $1 \mathrm{mTorr}$. XRD $\theta-2 \theta$ patterns of film in Figure 1a show the peak at $2 \theta=36.02^{\circ}$, which comes from the $\mathrm{Cr}_{2} \mathrm{O}_{3}$ [11-20] Bragg reflection corresponding to the corundum structure. The peak at $37.8^{\circ}$ is the $[11-20] \mathrm{Al}_{2} \mathrm{O}_{3}$ substrate peak. The films grown at oxygen flow varying from 2.0 to $3.5 \mathrm{sccm}$ show similar structure with different strains in the films as discussed in detail below. It was, however, found that when the amount of $\mathrm{O}_{2}$ in the gas mixture was above $5.0 \mathrm{sccm}$, the deposition rate decreased sharply. This finding is consistent with the previously reported results [18].

Figure $1 \mathrm{~b}$ shows the rocking curve data for the [11-20] Bragg reflection of the same 20-nm $\mathrm{Cr}_{2} \mathrm{O}_{3}$ sample. The full width at half maximum value of the rocking curve is $0.145^{\circ}$. This indicates that the $\mathrm{Cr}_{2} \mathrm{O}_{3}$ film is formed with conformal a-axis orientation on the $\mathrm{Al}_{2} \mathrm{O}_{3}$ substrate. To confirm the epitaxial state of the in-plane orientation of the film, we performed the XRD $\Phi$-scan of the $\mathrm{Cr}_{2} \mathrm{O}_{3}$ film from $-190^{\circ}$ to $190^{\circ}$ (see Figure 1c). The $\Phi$-scanning result from the $\mathrm{Cr}_{2} \mathrm{O}_{3}$ films indicates that there are two equivalent peaks, each being separated by $180^{\circ}$. These commensurate peak positions of the film and the substrate confirm the epitaxial relationship between the two. And this two-fold symmetry of the deposited film indicates that the film consists of a single crystalline domain.

We deposited both $\mathrm{Cr}_{2} \mathrm{O}_{3}$ and $\mathrm{Fe}_{2} \mathrm{O}_{3}$ samples by varying the flow rate of oxygen. The XRD $\theta-2 \theta$ scan of the $\mathrm{Cr}_{2} \mathrm{O}_{3}$ thin films deposited with different oxygen flow are shown in Figure 2. The thickness of the films deposited at $3.5 \mathrm{sccm}$ is $10 \mathrm{~nm}$, while it is $20 \mathrm{~nm}$ for the other films deposited films. For both 2.5 and $3.0 \mathrm{sccm}$, the $\mathrm{Cr}_{2} \mathrm{O}_{3}$ peaks show finite size oscillations up to the fifth order, which confirms low surface roughness of these films. However, the film deposited with $3.5 \mathrm{sccm}$ pressure shows a much broader XRD peak. The broadening may result from the shorter out of plane coherence length in thinner film [19]. Thus, for the subsequent depositions, we choose the oxygen flow of $2.5 \mathrm{sccm}$ for 
all the deposition conditions as this flow of oxygen provides the optimum oxidation for both oxides.

(a)

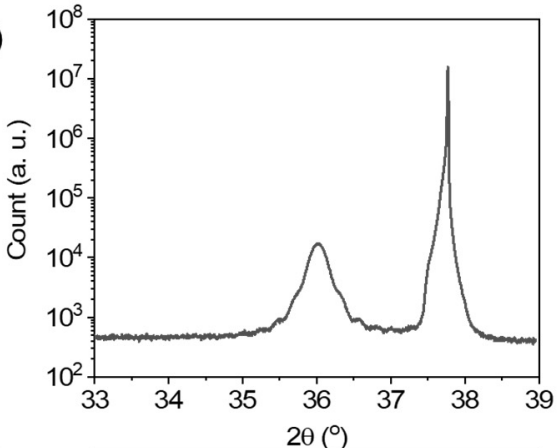

(b)

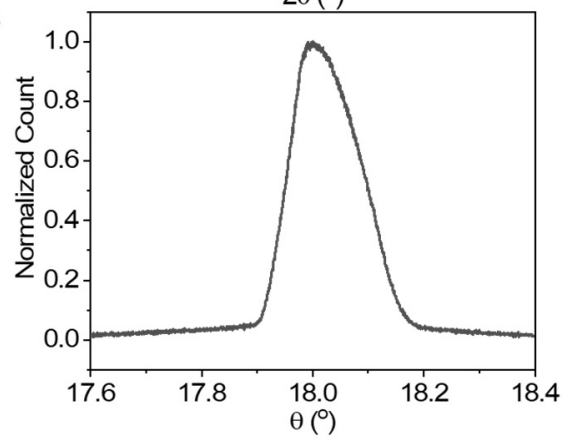

(c)

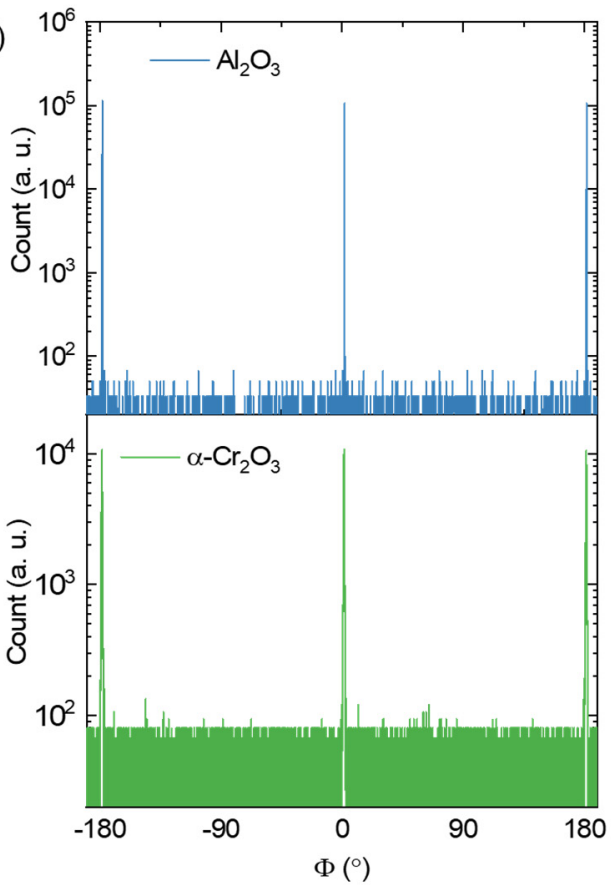

Figure 1. (a) XRD $\theta-2 \theta$ patterns of the $\mathrm{Cr}_{2} \mathrm{O}_{3}$ epitaxial film grown on an $[11 \overline{2} 0] \mathrm{Al}_{2} \mathrm{O}_{3}$ substrate. (b) XRD $\theta$-rocking curve $\mathrm{Cr}_{2} \mathrm{O}_{3}$ film. (c) XRD $\Phi$-scan results of the $\mathrm{Cr}_{2} \mathrm{O}_{3}$ and $\mathrm{Al}_{2} \mathrm{O}_{3}$ reflections.

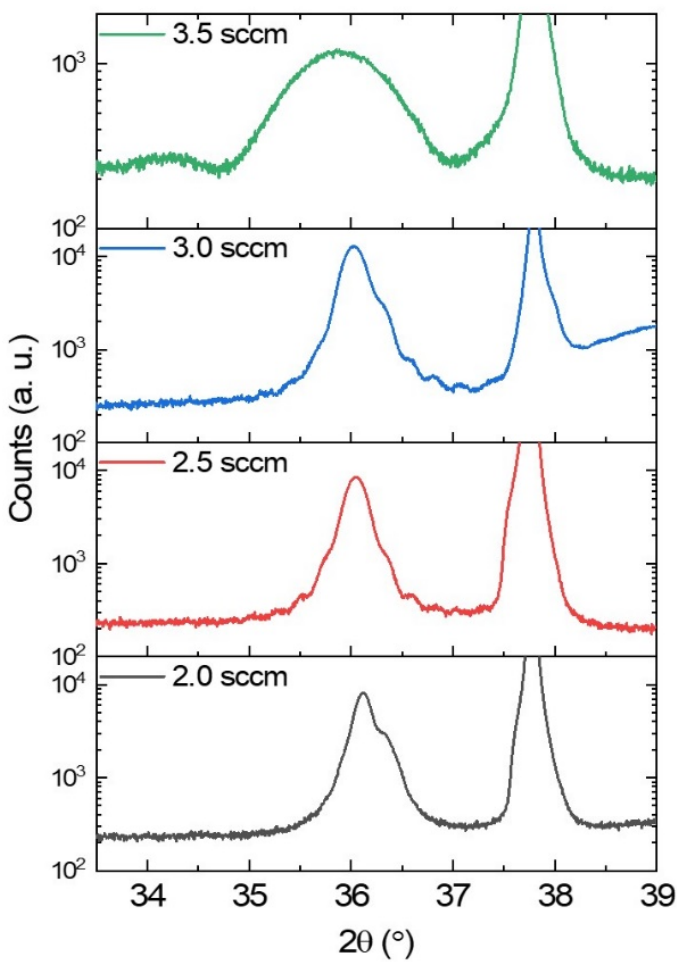

Figure 2. $\theta-2 \theta$ scan of $\mathrm{Cr}_{2} \mathrm{O}_{3}$ thin films deposited with different oxygen flow at a deposition pressure of $5 \mathrm{mTorr}$ and temperature of $675^{\circ} \mathrm{C}$ with $150 \mathrm{~W}$ RF power.

We characterize the roughness of the $\mathrm{Cr}_{2} \mathrm{O}_{3}$ epitaxial films using XRR. Figure $3 \mathrm{a}, \mathrm{b}$ shows the roughness at different deposition temperatures as a function of $\mathrm{O}_{2}$ flow and 
deposition pressure, respectively. All the $\mathrm{Cr}_{2} \mathrm{O}_{3}$ films shown in Figure 3a were deposited with a chamber pressure of 5 mTorr. The roughness of the $\mathrm{Cr}_{2} \mathrm{O}_{3}$ films is lowest at the oxygen flow rate of $2.5 \mathrm{sccm}$ and the deposition temperature of $675^{\circ} \mathrm{C}$. The roughness of the films increases for both lower and higher oxygen flow rate. Figure 3 a also shows the in-plane compressive strain in $\mathrm{Cr}_{2} \mathrm{O}_{3}$ deposited at $675{ }^{\circ} \mathrm{C}$ due to lattice mismatch between the thin films and the sapphire substrate. Figure $3 \mathrm{~b}$ shows that the roughness of the films gradually decreases for higher deposition pressure. We limit the deposition pressure to 5 mTorr to obtain an epitaxial films film with low surface roughness while the deposition rate is still reasonable $(3.5 \AA / \mathrm{s})$. The low surface roughness of these antiferromagnet oxide films is important for the low damping of the magnon modes [20].

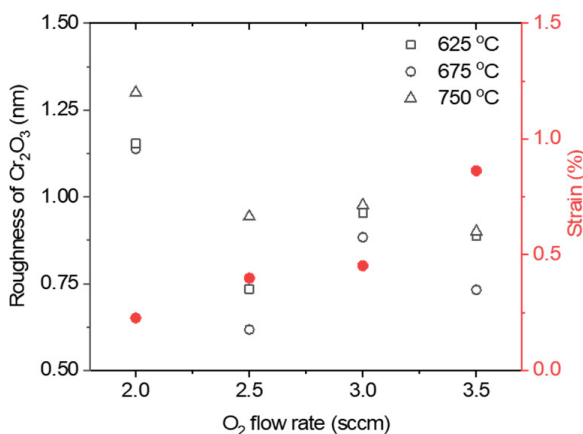

(a)

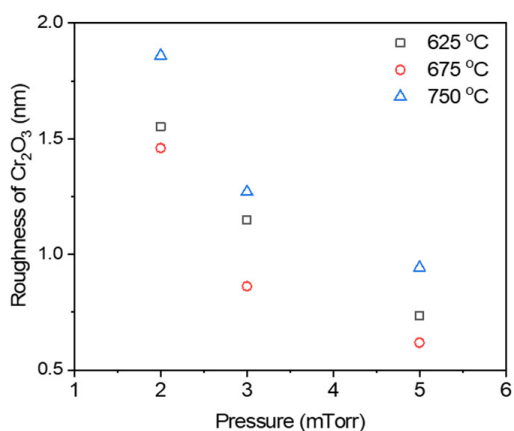

(b)

Figure 3. (a) Surface roughness of $\mathrm{Cr}_{2} \mathrm{O}_{3}$ films with thickness of $20 \mathrm{~nm}$ deposited at different temperature and in-plane compressive strain in $\mathrm{Cr}_{2} \mathrm{O}_{3}$ at $675^{\circ} \mathrm{C}$ as a function of oxygen flow rate. The open symbols show the surface roughness, and the filled circles show the in-plane strain in $\mathrm{Cr}_{2} \mathrm{O}_{3}$ films. (b) Surface roughness of the films as a function of deposition pressure.

Figure 4 shows the XRD data of a 200-nm $\mathrm{Fe}_{2} \mathrm{O}_{3}$ film on an A-plane sapphire substrate. The peak at $35.6^{\circ}$ is the [11-20] peak of $\alpha-\mathrm{Fe}_{2} \mathrm{O}_{3}$. This film is capped with $5 \mathrm{~nm}$ of Pt. The broader peak at $39.5^{\circ}$ shows the [111] XRD peak of the Pt layer. It was deposited on $\mathrm{Fe}_{2} \mathrm{O}_{3}$ at room temperature at a deposition pres $\times 3 \mu \mathrm{m}$ area and found to be only $3 \AA$ (Figure 5). The in-plane $\Phi$ XRD-scan of the $\alpha-\mathrm{Fe}_{2} \mathrm{O}_{3}$ film indicates two-fold symmetry along the $<11 \overline{2} 0>$ direction, and therefore, single crystalline domain structure. The roughnesses of thinner $\alpha-\mathrm{Fe}_{2} \mathrm{O}_{3}$ films show a similar trend with the oxygen flow and deposition pressure as observed for the $\mathrm{Cr}_{2} \mathrm{O}_{3}$.

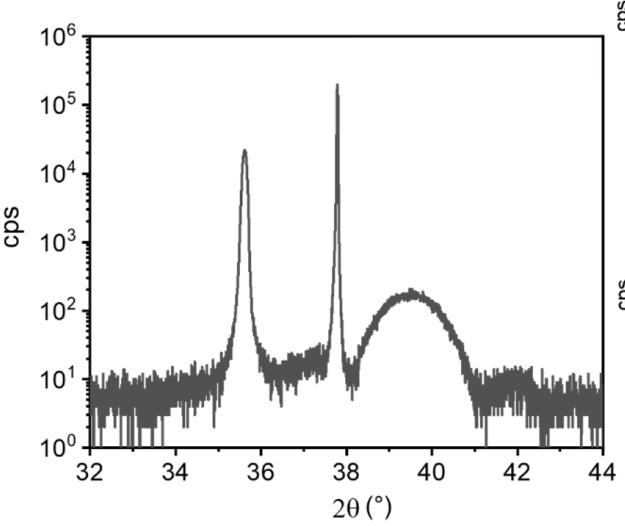

(a)

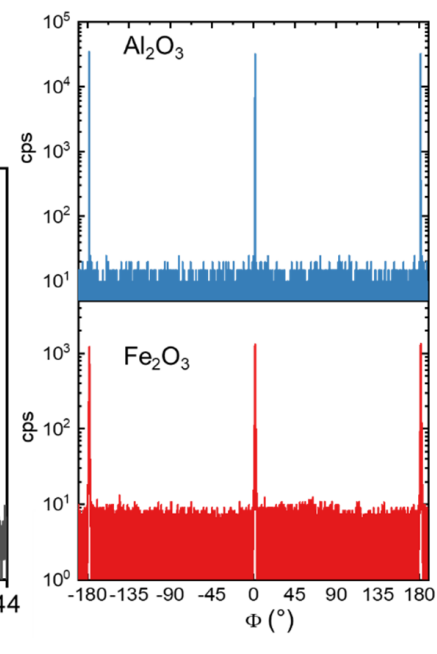

(b)

Figure 4. (a) XRD $\theta-2 \theta$ patterns of the $\alpha-\mathrm{Fe}_{2} \mathrm{O}_{3}$ epitaxial film grown on an [1120] $\mathrm{Al}_{2} \mathrm{O}_{3}$ substrate. (b) XRD $\Phi$-scan results of the $\alpha-\mathrm{Fe}_{2} \mathrm{O}_{3}$ and $\mathrm{Al}_{2} \mathrm{O}_{3}$ reflections. 


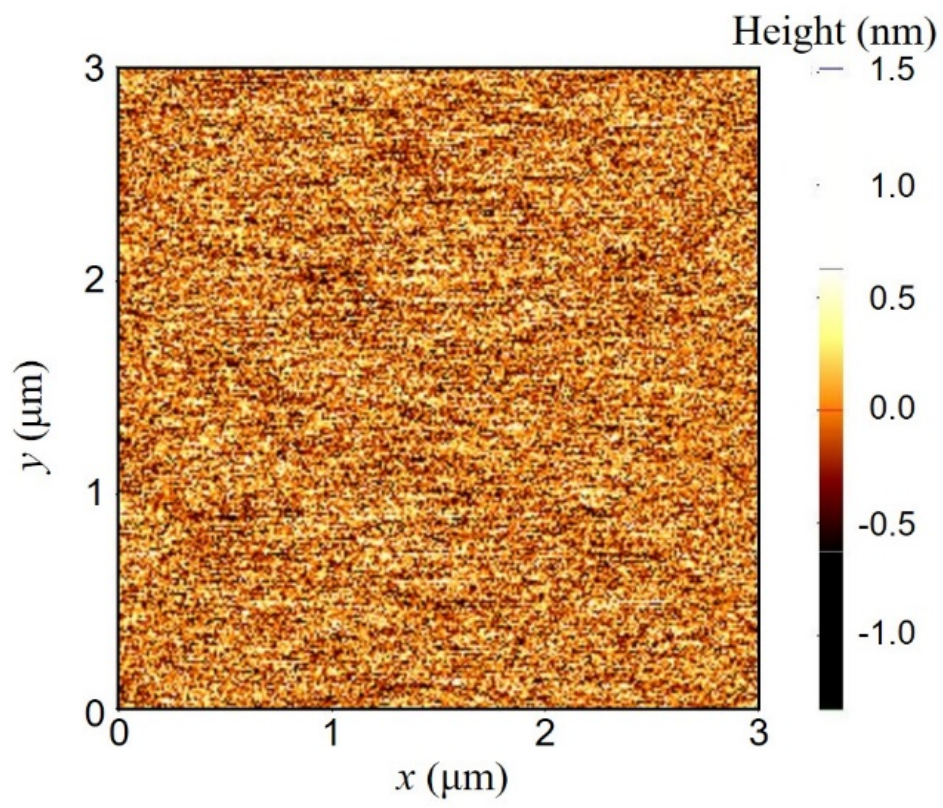

Figure 5. Atomic force micrograph of $200 \mathrm{~nm}$ thick $\alpha-\mathrm{Fe}_{2} \mathrm{O}_{3}$ film.

\subsection{Magnetic Properties}

$\mathrm{Cr}_{2} \mathrm{O}_{3}$ and $\alpha-\mathrm{Fe}_{2} \mathrm{O}_{3}$ are both antiferromagnetic materials. To confirm the absence of any residual magnetism in $\mathrm{Cr}_{2} \mathrm{O}_{3}$ and $\alpha-\mathrm{Fe}_{2} \mathrm{O}_{3}$ films, SQUID measurements were performed with magnetic fields of 0.4 and $0.2 \mathrm{~T}$, respectively, applied perpendicular to the A-plane of the substrates. For the SQUID measurement, a $5 \times 5 \mathrm{~mm}$ sample is loaded in the chamber inside a straw. The sample plane is perpendicular to the magnetic field. Figure 6 shows the magnetization of the epitaxial oxide films as a function of temperature. There is no hysteresis present in the magnetization data between the heating and cooling of the $\mathrm{Cr}_{2} \mathrm{O}_{3}$ films from 5 to $320 \mathrm{~K}$ and, of the $\alpha-\mathrm{Fe}_{2} \mathrm{O}_{3}$ films from 5 to $350 \mathrm{~K}$. For the 20-nm $\mathrm{Cr}_{2} \mathrm{O}_{3}$ films, the magnetization is almost zero, which identifies the antiferromagnetic exchange interaction between $\mathrm{Cr}^{3+}$ ions in neighboring layers [21]. There is no significant difference observed between the zero-field cooled (ZFC) and the field cooled (FC) measurements. For the FC measurement, the sample is cooled to $5 \mathrm{~K}$ from $320 \mathrm{~K}$ with a magnetic field of $2 \mathrm{~T}$ applied perpendicular to the A-plane of the substrate. We noticed a very small $\left(0.01 \mathrm{emu} / \mathrm{cm}^{3}\right)$ increase in the magnetization at $40 \mathrm{~K}$ for $20-\mathrm{nm} \mathrm{Cr}_{2} \mathrm{O}_{3}$ epitaxial films. This minuscule magnetization comes from the magnetic impurities present in the sapphire substrates as confirmed by measuring the magnetization of only the substrate as a function of temperature (data not presented). The inset of Figure 6a shows the spin orientation of the $\mathrm{Cr}^{3+}$ ions inside a unit cell of $\mathrm{Cr}_{2} \mathrm{O}_{3}$. The spins are pointing along the c-axis of the sample for all temperatures.

In $\alpha-\mathrm{Fe}_{2} \mathrm{O}_{3}$, the antiferromagnetic spin configuration changes its direction from being parallel to the [0001] axis to being in the (0001) basal plane at temperatures above the Morin temperature $\left(T_{\mathrm{M}}\right)$. The Morin transition is due to the Dzyaloshinskii-Moriya interaction, where asymmetric exchange interaction between two neighboring spins results in a weak net magnetic moment in the (0001) plane at temperatures above $T_{M}$ [22]. Figure $4 b$ shows the temperature dependence of the out-of-plane magnetization of a 200-nm thick $\alpha-\mathrm{Fe}_{2} \mathrm{O}_{3}$ film under an applied field of $0.2 \mathrm{~T}$. An increase of the magnetization is observed above $225 \mathrm{~K}$, which is lower than in bulk samples $(\approx 260 \mathrm{~K})$ [22]. The enhanced magnetization reflects a weak net ferromagnetic moment at temperatures above $T_{\mathrm{M}}$. For thinner $\alpha$ $\mathrm{Fe}_{2} \mathrm{O}_{3}$ samples, we did not observe the Morin transition. The lowering of the transition temperature in thinner films may result from the increased in-plane strain in those films. The Morin transition is usually determined by the competition between the magnetic dipolar and the structural anisotropy energies. The temperature variations of these two energy contributions have quantum statistical basis and are different [23]. It is possible that 
their temperature variations change compared to bulk crystals because of the presence of strain in the film, which eventually eliminates the secondary transition.

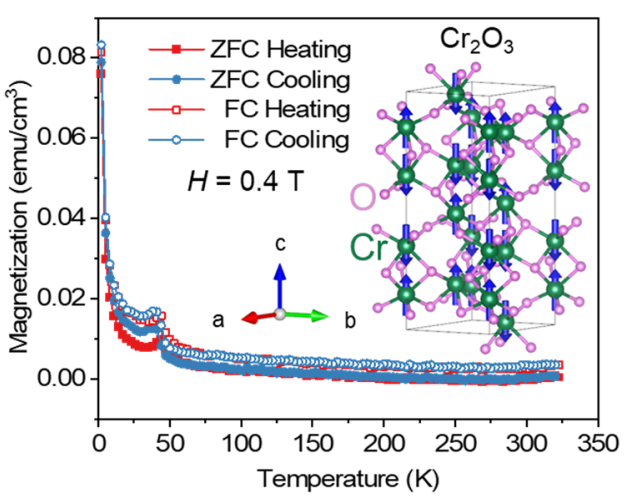

(a)

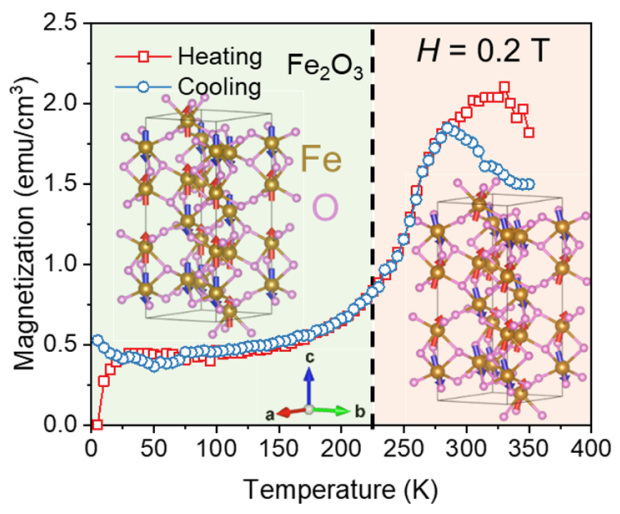

(b)

Figure 6. Magnetization of (a) $\mathrm{Cr}_{2} \mathrm{O}_{3}$, (b) $\alpha-\mathrm{Fe}_{2} \mathrm{O}_{3}$ epitaxial films along the a-axis as a function of temperature. A magnetic field of $2 \mathrm{~T}$ is applied perpendicular to the A-plane during the field-cooling for the $\mathrm{Cr}_{2} \mathrm{O}_{3}$ film. The inset of (a) shows the unit cell of $\mathrm{Cr}_{2} \mathrm{O}_{3}$ with the spin orientations for the $\mathrm{Cr}^{3+}$ ions. The insets of (b) show the unit cells of $\alpha-\mathrm{Fe}_{2} \mathrm{O}_{3}$ with the spin orientations for the $\mathrm{Fe}^{3+}$ ions before and after the Morin transition.

\section{Conclusions}

In summary, we have shown a detailed study of radio frequency magnetron sputtering of epitaxial thin films of $\mathrm{Cr}_{2} \mathrm{O}_{3}$ and $\alpha-\mathrm{Fe}_{2} \mathrm{O}_{3}$ on A-plane sapphire substrates for spintronic applications. Optimized sputtering conditions are discussed together with the characterizations of the crystal orientations and magnetic properties of these films. These single domain antiferromagnetic oxide thin films will be very important for studying the magnon dynamics and transport for extremely low-loss spintronic devices. They can also potentially be used for antiferromagnetic ultra-dense memory with $\mathrm{THz}$ bandwidth by utilizing current induced magnetization reversal. In addition, our developed deposition method confirms the single domain properties of these films, which is essential to reproduce many exciting magnon properties, which were previously observed only in single crystal oxides. Our epitaxial sputtering method will pave the way for the potential application of antiferromagnetic oxides in the field of electronics.

Author Contributions: S.A.S. conceived, designed and performed the experiments, and analyzed the data. D.H. helped with the $\alpha-\mathrm{Fe}_{2} \mathrm{O}_{3}$ structural characterization. J.E.P. helped with the deposition and characterization of the $\alpha-\mathrm{Fe}_{2} \mathrm{O}_{3}$ films. S.A.S. and A.H. co-wrote the paper. All authors have read and agreed to the published version of the manuscript.

Funding: The growth and the characterization of $\alpha-\mathrm{Fe}_{2} \mathrm{O}_{3}$ films were supported by the US Department of Energy, Office of Science, Basic Energy Sciences, Materials Sciences and Engineering Division. The use of facilities at the Center for Nanoscale Materials, an Office of Science user facility, was supported by the US Department of Energy, Basic Energy Sciences under Contract No. DE-AC0206CH11357. The growth and the characterization of $\mathrm{Cr}_{2} \mathrm{O}_{3}$ films were supported by the National Science Foundation (NSF) through the University of Illinois at Urbana-Champaign Materials Research Science and Engineering Center No. DMR-1720633 and was carried out in part in the Materials Research Laboratory Central Research Facilities, University of Illinois.

Institutional Review Board Statement: Not applicable.

Informed Consent Statement: Not applicable.

Data Availability Statement: The data presented in this study are available on request from the corresponding author. 
Conflicts of Interest: The authors declare no conflict of interest. The funders had no role in the design of the study; in the collection, analyses, or interpretation of data; in the writing of the manuscript, or in the decision to publish the results.

\section{References}

1. Wang, H.; Du, C.; Hammel, P.C.; Yang, F. Antiferromagnonic spin transport from $\mathrm{Y}_{3} \mathrm{Fe}_{5} \mathrm{O}_{12}$ into NiO. Phys. Rev. Lett. 2014, 113, 097202. [CrossRef]

2. Hahn, C.; de Loubens, G.; Naletov, V.V.; Ben Youssef, J.; Klein, O.; Viret, M. Conduction of spin currents through insulating antiferromagnetic oxides. EPL Europhys. Lett. 2014, 108, 57005. [CrossRef]

3. Seki, S.; Ideue, T.; Kubota, M.; Kozuka, Y.; Takagi, R.; Nakamura, M.; Kaneko, Y.; Kawasaki, M.; Tokura, Y. Thermal generation of spin current in an antiferromagnet. Phys. Rev. Lett. 2015, 115, 266601. [CrossRef]

4. Wu, S.M.; Zhang, W.; Kc, A.; Borisov, P.; Pearson, J.E.; Jiang, J.S.; Lederman, D.; Hoffmann, A.; Bhattacharya, A. Antiferromagnetic spin seebeck effect. Phys. Rev. Lett. 2016, 116, 097204. [CrossRef]

5. Luo, Y.; Liu, C.; Saglam, H.; Li, Y.; Zhang, W.; Zhang, S.S.; Pearson, J.E.; Fisher, B.; Zhou, T.; Bhattacharya, A.; et al. Distinguishing antiferromagnetic spin sublattices via the spin Seebeck effect. Phys. Rev. B 2021, 103, L020401. [CrossRef]

6. Li, J.; Wilson, C.B.; Cheng, R.; Lohmann, M.; Kavand, M.; Yuan, W.; Aldosary, M.; Agladze, N.; Wei, P.; Sherwin, M.S.; et al. Spin current from sub-terahertz-generated antiferromagnetic magnons. Nature 2020, 578, 70-74. [CrossRef]

7. Vaidya, P.; Morley, S.A.; van Tol, J.; Liu, Y.; Cheng, R.; Brataas, A.; Lederman, D.; del Barco, E. Subterahertz spin pumping from an insulating antiferromagnet. Science 2020, 368, 160. [CrossRef]

8. Yuan, W.; Zhu, Q.; Su, T.; Yao, Y.; Xing, W.; Chen, Y.; Ma, Y.; Lin, X.; Shi, J.; Shindou, R.; et al. Experimental signatures of spin superfluid ground state in canted antiferromagnet $\mathrm{Cr}_{2} \mathrm{O}_{3}$ via nonlocal spin transport. Sci. Adv. 2018, 4, eaat1098. [CrossRef]

9. Lebrun, R.; Ross, A.; Bender, S.A.; Qaiumzadeh, A.; Baldrati, L.; Cramer, J.; Brataas, A.; Duine, R.A.; Kläui, M. Tunable long-distance spin transport in a crystalline antiferromagnetic iron oxide. Nature 2018, 561, 222-225. [CrossRef]

10. Lebrun, R.; Ross, A.; Gomonay, O.; Baltz, V.; Ebels, U.; Barra, A.L.; Qaiumzadeh, A.; Brataas, A.; Sinova, J.; Klaui, M. Longdistance spin-transport across the Morin phase transition up to room temperature in ultra-low damping single crystals of the antiferromagnet $\alpha-\mathrm{Fe}_{2} \mathrm{O}_{3}$. Nat. Commun. 2020, 11, 6332. [CrossRef]

11. Zhang, P.; Finley, J.; Safi, T.; Liu, L. Quantitative study on current-induced effect in an antiferromagnet insulator/Pt bilayer film. Phys. Rev. Lett. 2019, 123, 247206. [CrossRef]

12. Kosub, T.; Kopte, M.; Hühne, R.; Appel, P.; Shields, B.; Maletinsky, P.; Hübner, R.; Liedke, M.O.; Fassbender, J.; Schmidt, O.G.; et al. Purely antiferromagnetic magnetoelectric random access memory. Nat. Commun. 2017, 8, 13985. [CrossRef]

13. Ramazanov, S.; Sobola, D.; Orudzhev, F.; Knápek, A.; Polčák, J.; Potoček, M.; Kaspar, P.; Dallaev, R. Surface modification and enhancement of ferromagnetism in $\mathrm{BiFeO}_{3}$ nanofilms deposited on HOPG. Nanomaterials 2020, 10, 1990. [CrossRef] [PubMed]

14. Speriosu, V.S.; Herman, D.A.; Sanders, I.L.; Yogi, T. Magnetic thin films in recording technology. IBM J. Res. Dev. 1990, 34, 884-902. [CrossRef]

15. Leighton, C.; Hoffmann, A.; Fitzsimmons, M.R.; Nogués, J.; Schuller, I.K. Deposition of epitaxial $\alpha-\mathrm{Fe}_{2} \mathrm{O}_{3}$ layers for exchange bias studies by reactive dc magnetron sputtering. Philos. Mag. B 2001, 81, 1927-1934. [CrossRef]

16. Valeri, S.; Altieri, S.; Luches, P. Growth of antiferromagnetic oxide thin films. Magn. Prop. Antiferromagn. Oxide Mater. 2010, 25-68. [CrossRef]

17. Shimomura, N.; Pati, S.P.; Sato, Y.; Nozaki, T.; Shibata, T.; Mibu, K.; Sahashi, M. Morin transition temperature in (0001)-oriented $\alpha-\mathrm{Fe}_{2} \mathrm{O}_{3}$ thin film and effect of Ir doping. J. Appl. Phys. 2015, 117, 17C736. [CrossRef]

18. Rothhaar, U.; Oechsner, H. Rf magnetron sputter deposition of $\mathrm{Cr}_{2} \mathrm{O}_{3}$ layers on ceramic $\mathrm{Al}_{2} \mathrm{O}_{3}$ substrates. Surf. Coat. Technol. 1993, 59, 183-186. [CrossRef]

19. Vayunandana Reddy, Y.K.; Wolfman, J.; Autret-Lambert, C.; Gervais, M.; Gervais, F. Strain relaxation of epitaxial $\left(\mathrm{Ba}_{0.6} \mathrm{Sr}_{0.4}\right)\left(\mathrm{Zr}_{0.3} \mathrm{Ti}_{0.7}\right) \mathrm{O}_{3}$ thin films grown on $\mathrm{SrTiO}_{3}$ substrates by pulsed laser deposition. J. Appl. Phys. 2010, $107,106101$.

20. Yu, T.; Sharma, S.; Blanter, Y.M.; Bauer, G.E. Surface dynamics of rough magnetic films. Phys. Rev. B 2019, 99, 174402. [CrossRef]

21. Nozaki, T.; Al-Mahdawi, M.; Shiokawa, Y.; Pati, S.P.; Imamura, H.; Sahashi, M. Magnetic anisotropy of doped $\mathrm{Cr}_{2} \mathrm{O}_{3}$ antiferromagnetic films evaluated by utilizing parasitic magnetization. J. Appl. Phys. 2020, 128, 023901. [CrossRef]

22. Morin, F.J. Electrical properties of $\alpha \mathrm{Fe}_{2} \mathrm{O}_{3}$ and $\alpha \mathrm{Fe}_{2} \mathrm{O}_{3}$ containing titanium. Phys. Rev. 1951, 83, 1005-1010. [CrossRef]

23. Artman, J.O.; Murphy, J.C.; Foner, S. Magnetic anisotropy in antiferromagnetic corundum-type sesquioxides. Phys. Rev. 1965, 138, A912-A917. [CrossRef] 